\title{
A Novel Engineering Spherical Bearing, with Potential Application for a Hip Implant
}

\author{
Virgil Florescu ${ }^{1}$, Lucian Capitanu ${ }^{2}$, Liliana-Laura Badita ${ }^{3}$ and Viviana Filip ${ }^{4}$ \\ 1. The Mechanical Department, Institute of Civil Engineering, Bucharest 010153, Romania \\ 2. The Tribology Department, Institute of Solid Mechanics of the Romanian Academy, Bucharest 010141, Romania \\ 3. INCD-Mechatronics \& Measurement Technique, Bucharest 021631, Romania \\ 4. Institute of Multidisciplinary Research for Science and Technology, Valahia University of Targoviste, Targoviste 130004, \\ Romania
}

\begin{abstract}
It is a research which could enter into contradiction with the current trend concerning the hip implants. It is known as sliding friction, which is characteristic of present artificial hip joints, is higher than in the case of rolling friction. The paper reports the studies of the functioning mode of a novel spherical bearing MoM (metal on metal) with rolling friction, with potential application for an artificial hip joint obtained by introducing a number of balls between the femoral head and the acetabular cup. After over 15 years of research upon the functional principle and constructive solution, a version that offered a coefficient of minimum friction in the hip joint came to light. This version was based on a constructive solution of motion with lower friction, "Omnitrack ${ }^{\circledR}$ movement solutions", which has been modified and rebuilt to be used as a joint of a total hip prosthesis-MOMJ. The joint was built entirely in stainless steel, SS316L medical grade. Tests have been carried out on the experimental laboratory devices that showed very low values of the coefficient of friction $(\mu=0.0225)$. For validation, the prosthesis had to be put through tests for 500,000 cycles, in terms of physiological motion and dynamic loading, according to ISO 14242-3. Testing was conducted on a multiaxial dynamics machine, MTS Bionix, equipped with system for hip implant testing. The testing results of this total hip prosthesis with rolling friction have been successful in signing up for a friction moment of $0.525 \mathrm{kNmm}$ which means a coefficient of friction $\mu=0.0143$, for a joint with femoral head diameter $28 \mathrm{~mm}$.
\end{abstract}

Key words: Spherical joint, total hip prosthesis, rolling friction, balls, femoral head surface wear, Omnitrack ${ }^{\circledR}$ movement solutions, laboratory testing.

\section{Introduction}

In over 20 years of research in the field of loosening and wear of orthopaedic endoprosthesis, the authors conducted research from a tribological view oriented to the screening of the causes determining the failure of the prosthesis removed after replacement surgery. Multiple causes have been identified including the loosening of the cemented stems, breakage of the press-fitted stems, femoral heads scratching due to particles of cement, bone or peeling coatings thin layers of femoral heads, embedding of wear particles in acetabular cups surfaces, etc.

Corresponding author: Lucian Capitanu, Prof. Dr. Eng., research fields: tribology and biotribology.
Pending its function, the femoral head of a total hip prosthesis suffered a series of damages in the human body leading eventually to the failure of the prosthesis. Current practice in the manufacture of total hip prosthesis is to make a base alloy femoral head in order to take over the mechanical forces, with a monolayer covered surface or multilayer hard coatings, friction and wear resistant. Co-Cr and titanium based alloys (Ti6Al4V) are the most used materials. The physical characteristics of titanium, the strength, hardness, high durability, low density, corrosion resistance and biological compatibility, make it useful in a variety of biomedical applications. Titanium in the form of thin film is used to protect or improve the surface properties of various materials. Many applications of titanium 
thin films require knowledge of its tribological behaviour. Ti6Al4V alloy has excellent corrosion resistance, biocompatibility, high strength in relation to its weight and also a great tenacity, for these reasons it is an alloy widely used for advanced biomedical applications [1].

However, the tribological properties of these alloys are known to be weak, especially in abrasion and sliding [2]. Several surface treatments pursuing to improve tribological properties of this alloy, including plasma nitriding [3], ion implantation by plasma immersion [4], laser nitriding [5], PVD (physical vapour deposition) [6] were taken on board. Among various processes, PVD coatings can be produced at lower temperatures and therefore it has the advantage of fewer adverse effects on mechanical properties of the substrate. Many studies have been produced regarding Ti6Al4V alloy coated with either a single coating $[7,8]$ or by duplex approach that increases the load borne by the substrate: nitriding TiN [9], HVOF WC-Co/TiN [10], nitriding/DLC [11], deep hardening oxygen/DLC [12]. The tribosystem friction properties strongly depend on the properties of materials, the external environment and the nature of the wear particles generated during sliding [13]. The way a surface is deformed will dictate the nature of the wear particles generated, which in turn can significantly influence the wear behaviour of materials. The tribofilms and wear particles generated during sliding are known to influence the behaviour of the materials friction [14]. Tribological mechanisms describe the macro-mechanical friction and wear phenomena by taking into account the distribution efforts - strains in the entire contact, total elastic and plastic deformations, formation process of the wear particles and its dynamics $[15,16]$.

More recently, it was analysed the effect of different mating materials on friction behaviour of TiN coatings with different crystallographic orientations [17]. It was noted that the formation of a titanium oxide layer on the surface leads to a lower value of friction. Many researchers aimed at studying the tribological behaviour of pure titanium metal and titanium alloys $[18,19]$. But reports on the wear behaviour of Ti thin layers are rare. Since titanium nitrides are hard biocompatible materials [20-22] with excellent resistance to abrasion, more advanced processing methods have been developed in order to achieve a nitride layer on the surface of materials. At the presence of nitride in plasma [23], nitrogen atoms diffuse into the titanium matrix, forming a layer of $\mathrm{TiN}$ and $\mathrm{Ti}_{2} \mathrm{~N}$ compounds, usually followed by a deeper diffusion layer. This layered structure produces a continuous profile of hardness, thus providing adequate support of the coating [21, 24]. However, the physical properties of treated surface are highly dependent on plasma coating technique and processing parameters.

Excellent corrosion resistance of titanium alloys resulted in the formation of a stable protective oxide film very strongly adhering to metal surfaces [25]. On the other hand, the corrosion resistance of $\mathrm{TiN}$ can be affected by its structural defects (pores, holes and small cracks) [23]. In fact, Capitanu et al. [26] showed that an adequate structure without defects and dense TiN film can significantly improve corrosion resistance. CoCrMo alloy is one of the most used implant alloys for artificial joints and offers a good combination of mechanical properties, corrosion resistance and biocompatibility. However, many investigations on femoral heads removed after replacement surgical interventions, showed numerous traces of wear on the surface of the prosthetic femoral head. In many studies [27-29] scratches, pits and coating peeling, sometimes even early traces of corrosion have been identified. Capitanu et al. [27] reported their findings regarding the head of a femoral prosthesis made from Ti6Al4V explanted after 10 years, from an athlete. They found severe deformation of it, but cold hardening in areas is subject to cyclic compression.

Due to this problem, theoretical and experimental research over the last 30 years have tried to contribute to the improvement of orthopaedic endoprostheses 
durability, through constructive changes and even through changing their functional principle.

Total hip prosthesis with wheels, is one of the first attempts to decrease wear, by replacing the sliding with the rolling movement for one degree of freedom of the joint. This solution, suggested by researchers from the Imperial College of Science, Technology and Medicine in London, consists of the constructive modification of the modular hip prosthesis by introducing a rolling bearing with conical wheels between the femoral stem neck and the femoral head [29]. It has been considered that a rolling bearing with conical wheels, that can support significant radial and axial loads, is most adequate for reaching this goal. But this requires a small diameter of the interior ring, imposed by the necessity of a reasonable diameter of the femoral head. Ensuring a satisfactory resistance for the bearing to challenge fatigue is also necessary, and changeability of the femoral head is also imposed. Regarding these constraints, a cylindrical wheels bearing has been considered. One must notice that rolling bearings with needles present a great durability to fatigue. The simulation was performed for 3 million loading cycles. After the first 500,000 cycles, oxidation of the femoral head was observed, manifested through colour changes. The colour of the interior acetabular cup's surface was also changed.

Other attempts regarding changing the constructive solution of total hip prosthesis took into consideration the fundamental change in the type of relative movement between the components of the total hip prosthesis. If, generally, the present technical solutions are based on the natural revolute movement of the femoral head in the acetabular cap, Katsutashi and Kiyoshi [30] imagine a different design, the total hip prosthesis with "balls train". This mainly consists of a dual joint construction. The artificial joint is composed of an interior sphere and an exterior cup restricting the movement of a train of balls mounted in a cage. By the characteristics of this design the movement is mainly by rolling.
The French idea of the "Supertête" prosthesis [31] consists of placing the friction contact inside a bearing. The solution belongs to "Fundation de l'Avenir" in collaboration with "La Direction Générale de l'Armement (Ministère de la Défense, Mission Innovation)". In the opinion of French researchers, this technical solution can reduce the wear of the prosthesis with almost $99 \%$. In order to reach this result, a small spherical bearing of an "absolutely new" type, as the authors claimed, lubricated with synovial fluid, the natural lubricant of any prosthesis, was integrated in the femoral head. Designed and built in accordance with aeronautics industry standards, the femoral head is claimed to have reduced wear, being designed to carry $25,000 \mathrm{~N}$, while the hip joint maximal forces do not overpass $5,000 \mathrm{~N}$. The authors estimate that this artificial joint is able to function more than 30 years for a frequency of loading of approximately 1 million of cycles/year.

Another kind of total hip prosthesis with balls is proposed by the Institute of Solid Mechanics, of the Romanian Academy, in collaboration with the University of Medicine, and the Universitary Hospital of Bucharest [29, 32-34], making the object of a Romanian Patent. Analysing some hip prostheses retrieved by revision, the appearance of some forms of polishing of the femoral head was observed, as well as significant plastic deformations followed by local hardening. At the same time, obvious traces of wearing through fretting of the acetabular cup of UHMWPE, which in some studies are confounded or assimilated with the adhesive wear, have been revealed. Starting with the well-known fact that the rolling movement always has a lower friction compared to sliding friction, the authors have conceived and realized a pivoting movement joint on a "layer of balls" with "compensation space", placed between the acetabular cup and the femoral head. This technical solution allows free self-directed migration of the balls, depending on the resistance opposed, with successive occupation of the "compensation space". As a concept, 
the proposed technical solution excludes the existence of a cage for maintaining the relative positions of the balls. This study targeted contact mechanism including friction and wear phenomena accounting. The proposed hip prosthesis, with self-directed rolling bodies, was made using a femoral head from Stelit 21, the acetabular metallic cup from Ti6A14V-ELI alloy and the balls from stainless steel. But experiments revealed a certain seizure in some strain conditions. The trials have been carried out in BSF (body simulated fluid) lubrication conditions, much closer to the real operating conditions up against the initial tests with distilled water. Laboratory trials for balls/plane Hertzian contacts have been restarted in order to determine seizure behaviour depending on the roughness of the flat area [35].

This was the cause for which we have abandoned this constructive version, but not the idea of achieving a total hip prosthesis with rolling friction. That is why I selected a variant of motion adopted after Omni Directional Movement Solutions from Omnitrack ${ }^{\mathrm{TM}}$. This variant of the low friction movement $(\mu=0.05)$ in the ball bearing was modified and adapted for use as constructive acetabular-femoral joint in a total hip prosthesis with the rolling friction (modified Omnitrack movement joint-MOMJ).

\section{Experimental Methods}

Based on Omni Directional Movement Solutions from Omnitrack ${ }^{\mathrm{TM}}$ - Fig. 1a, a few hip joints with balls (MOMJ) using femoral heads from classical MoP prosthesis-Figs. $1 \mathrm{~b}$ and $1 \mathrm{c}$ have been made. The hip implant joint is a spherical joint, a spatial rotating couple with 3 degrees of freedom, representing the three rotations around the coordinate axes $\left(\omega_{\mathrm{x}}, \omega_{\mathrm{y}}, \omega_{\mathrm{z}}\right)$. Therefore, this couple limits the 3 degrees of freedom, i.e., the three translations on axes. Translational constraints on the 3 coordinate axes are materializing forces $W_{\mathrm{x}}, W_{\mathrm{y}}$ and $W_{\mathrm{z}}-$ Fig. $1 \mathrm{~d}$. It can be seen from Fig. $1 \mathrm{c}$ that at this joint, the loading is transmitted to the femoral head via of the 106 balls, made from $316 \mathrm{~L}$ stainless steel -medical grade, and their movement is guided by a track of alumina ceramics with semispherical surfaces. The balls are moving freely in closed circuit between the two semispherical surfaces of the guide, external casing and femoral head. The inside guide of the balls is a femoral head of $28 \mathrm{~mm}$ diameter of a standard MoP prosthesis. In order to obtain the modified joint, the exterior component of the Omnitrack $^{\mathrm{TM}}$ solution has been processed by turning so that it could fit into a medical grade $316 \mathrm{~L}$ stainless steel casing and create the cocso-femoral prosthetic joint.

The Omnitrack ${ }^{\mathrm{TM}}$ movement solution-Fig. 1a also had its functioning position changed by $180^{\circ}$. The ball guide, pos. 1 in Fig. 1c, has been manufactured out of AmAlOx ceramic alumina in order to improve its seizure resistance. AmAlOx87 alumina (Astro Met Aluminum Oxide) comes from Astro Met, Inc., Cincinnati, OH, USA it is a high purity $99.8 \%$ aluminum oxide (alumina) ceramic which has been originally developed for critical load bearing medical implants, and optimized for maximum wear and corrosion resistance.

A high density, diamond like hardness, fine grain structure and superior mechanical strength are its unique properties that make the AmAlOx alumina the appropriate material for demanding applications. The typical properties of $\mathrm{AmAlOx} 87$ alumina include a bulk density of $3.97 \mathrm{~g} / \mathrm{cm}^{3}$, flexural strength of 482 MPa, Vickers hardness of 2,000 and a grain size of 2 microns. AmAlOx87 alumina has an unusually small grain size for an alumina ceramic and this enables extremely tight tolerances and surface finishes of 2 microinches $R_{\mathrm{a}}$ to be achieved. These joints have been first tested in laboratory on the same tester (Fig. 2) and under the same conditions (only with flexion-extension movement and with constant load) [35] as the previous version with the balls in self-directed motion (SDBJ), which has been abandoned. Fig. 2a shows an overall view of this device.

Monitoring of friction coefficient of hip prosthesis 
with the balls in self-directed motion (SDBJ) was compared to a classic metal on polyethylene prosthesis

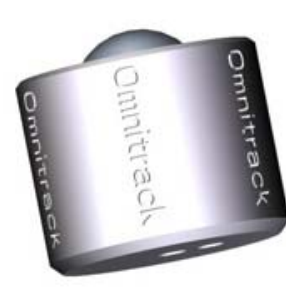

(a)

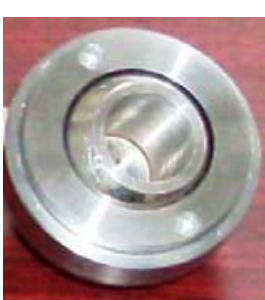

(b)

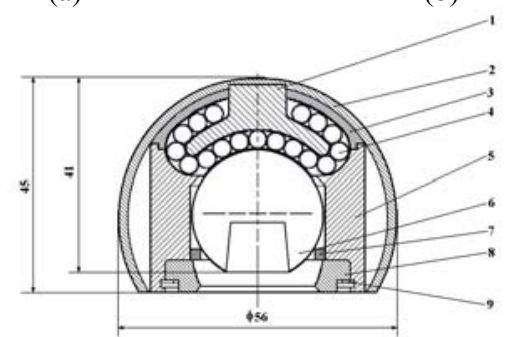

(c)

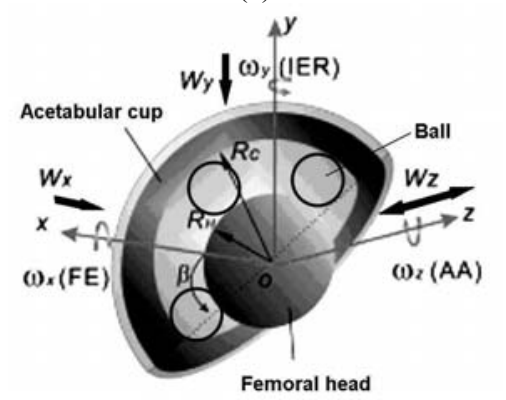

(d)
Fig. 1 (a) Stainless steel 316L Omnitrack ${ }^{\mathrm{TM}}$ joint with low friction $(\mu=0.005)$, maximum speed $2 \mathrm{~m} / \mathrm{s}$, high shock resistance; (b) view of the new joint; (c) scheme of the new acetabular-femoral joint (MOMJ), based on a modified Omnitrack movement solution: 1-balls guide; 2-outside casing; 3-superior handle; 4-balls; 5-lower handle; 6-femoral head; 7-silicone rubber liner; 8-lid; 9-“Spiralax" ring; and (d) rotational degrees of freedom and movement restrictions imposed by the translation spherical joint.

in anatomical position on an experimental test rig [35] that shows the kinematic diagram of this device. The device was built in such a way that the acetabular double piece is supported by only the two femoral heads that oscillate in two directions, similar to a hip. You can also see that the acetabular double piece moves at the same time as the femoral heads due to friction (item 8 and 10). The main features of this device are: simultaneous/alternative measurements of the friction coefficient; perfect timing in the kinematic and dynamic simulation of the hip joint; compliance with the angle formed by the load axis and the oscillation axis. The measured friction torque is a projection of the real torque, the latter resulting from the calculations. A cam till helicoidal compression spring (item 12) accomplishes the specific load to the hip articulation. The cam (item 13) was synthesized according to the loading diagram. The cam was rocked in the rotation of the chain-Fig. 2 b items 4, 15, 16, and a shaft (item 14). The flexion-extension movement was described by a quadrilateral gearing (pos. 5), which has turned the chain wheel rotation (item. 4) into an oscillation. Oscillation has been transmitted to the femoral head by means of a chain with bolts, with the ratio of $1: 1$ (Fig. 2, item 5) and a cardanic universal coupling.

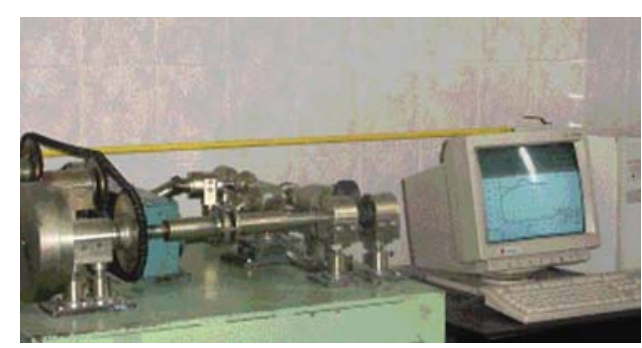

(a)

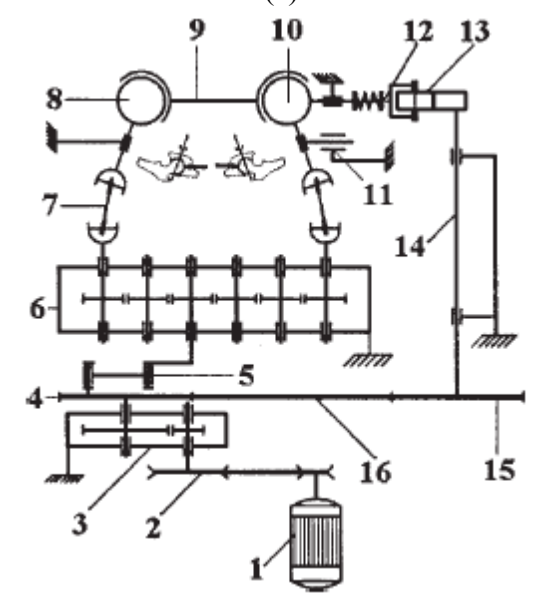

(b)

Fig. 2 (a) Device and (b) kinematic diagram of the testing device: 1-electromotor; 2-trapezoidal belts; 3-recurrent reducing gear; 4-wheel driving chain; 5-gear box; 6-gear reducer recurrent (periodic); 7-universal joint; 8 and 10-femoral heads; 9-acetabular double piece; 11-shaft; 12-coupling with wedge and pull spline; 13-cam; 14-shaft; 15-driven sprocket; 16-Gall's chain [35]. 
For each gait cycle determinations of the friction coefficient were made for the SDBJ (self-directed balls joint)-Fig. 3 and the modified Omnitrack movement solution-MOMJ—Fig. 4.

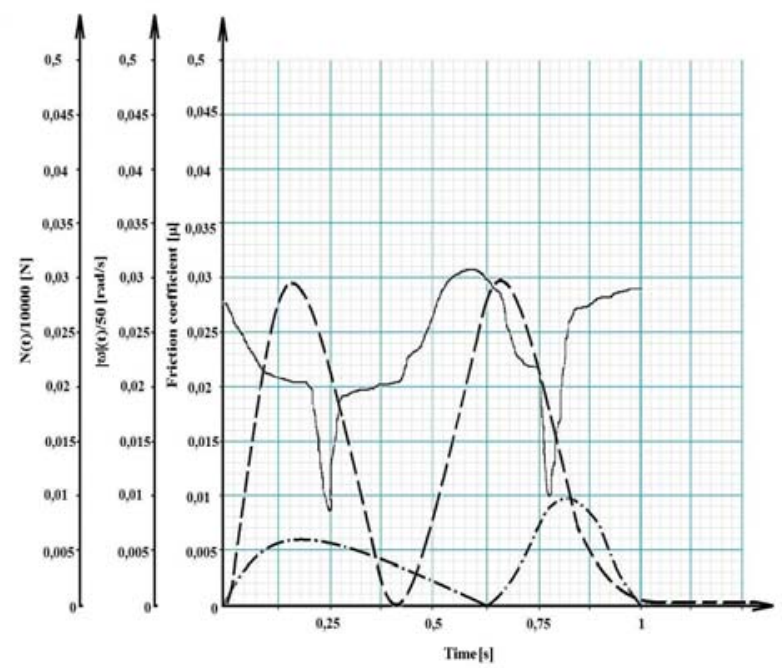

Fig. 3 Comparison between friction coefficient and the angular speed modulus, in case of acetabular-femoral joint with self-directed balls (SDBJ). It is to be noted the reverse dependency between friction coefficient and load and direct dependency with the angular velocity.

$-\mu(\mathrm{t}) ;-\cdot-N(\mathrm{t}) / 10,000 \mathrm{~N} ; \cdots|\omega|(t) / 25 \mathrm{rad} / \mathrm{s}$.

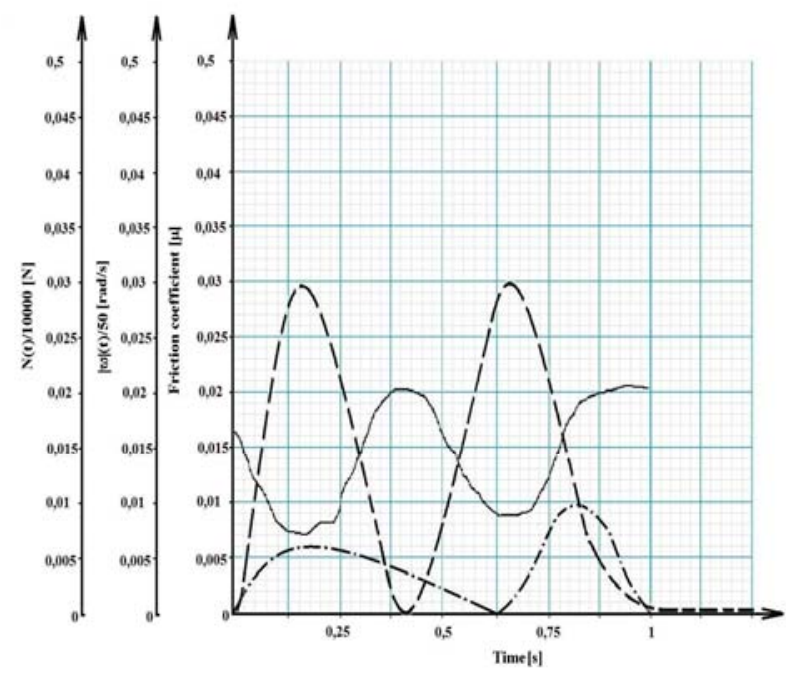

Fig. 4 Comparison between friction coefficient and the angular speed modulus, in case of modified Omnitrack movement acetabular-femoral joint-MOMJ joint in Fig. 1b. It is to be noted the reverse dependency between friction coefficient and load and direct dependency with the angular velocity.

$-\mu(\mathrm{t}) ;-\cdot-\cdot N(\mathrm{t}) / 10,000 \mathrm{~N} ; \cdots \omega(t) / 25 \mathrm{rad} / \mathrm{s}$.
With all the encouraging preliminary findings over MOMJ prosthesis behaviour, their validation was required using an approved system of dynamic multiaxial testing. For this purpose, we use a dynamic testing machine MTS Bionix (Fig. 5), equipped with a system for hip implants testing.

With all the encouraging preliminary findings over MOMJ prosthesis behaviour, their validation was required using an approved system of dynamic multiaxial testing.

MOMJ testing was made in comparison with the testing of a classical prosthesis MoP (CoCr-UHMWPE). MTS Bionix system for implants testing is equipped with three rotating motors for movement of the internal-external rotation; for flexion-extension movement and for movement of abduction-adduction and with three displacement transducers, one for the movement of abduction-adduction, an angular displacement transducer for flexion-extension movement and an angular displacement transducer for internal-external rotation movement. In addition, MTS Bionix system has a transducer for the moment of torsion, with two Wheatstone decks, one for measuring linear force and the other to measure the torsion moment. The moment transducer is of resistive type and it is coupled with a current converter type $66220 \mathrm{~h}-04$, to processing received signals from each deck Wheatstone.

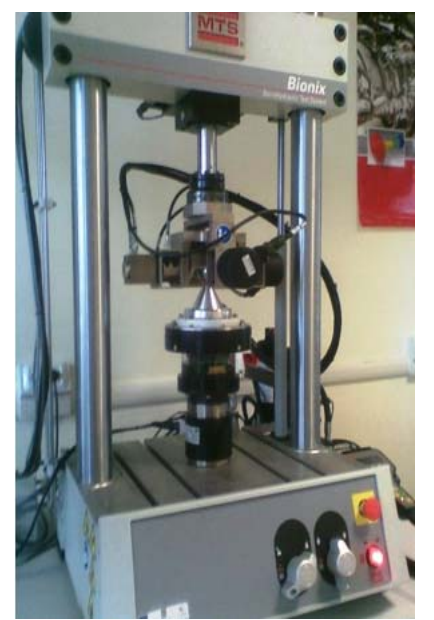

Fig. 5 Image of the positioning of the testing system on prototype. 
The test machine allowed setting number of cycles, the amount of the normal force on the joint implant (the force $F$ that has a pulsating form), the lower and upper limits of the angular displacement of each rotation, as well as the law of motion for each type of rotation according to ISO 14242-3.

Lubricant used was BSF (simulated body fluid) with the $1.183 \mathrm{~kg} / \mathrm{m}^{3}$ density and viscosity of $0.84 \mathrm{~Pa}$ (HyClone, SH 30212.03).

Before the time of the test, appropriate fitting of the sample was verified. It has been adjusted at the pump pressure value at $210 \mathrm{bar}$, started the controller and application "Station Manager", in which they were made related to the system calibration settings and adjust.

After the command-response adjustments, have zeroed the value output for each axis (axial, torsion, flexion/extension, abduction/adduction, internal/external rotation). Support for testing of modular femoral heads is presented in Fig. 6.

Through the "ELITE" software the vertical push force and the displacement angles were set: flexion-extension, abduction-adduction, internal-external rotation, according to ISO 14242 upgraded in 2014, which sets the parameters for orthopaedic implants testing (axial force, abduction-adduction, internal-external rotation and flexion-extension angle).

After entering values for force and angle of movement in flexion-extension, abduction-adduction, internal-external rotation, it was set the number of test cycles to 50,000 cycles. To test the MOMJ joint, it was considered the fact that a human subject's movement of flexion-extension in one second ( $1 \mathrm{~s})$, is one cycle per second.

\section{Results and Discussion}

The prototype was subjected to simultaneous requests of flexion-extension, abduction-adduction and internal-external rotation during a cycle and was considered a time of $5 \mathrm{~s}$, where human subject achieves

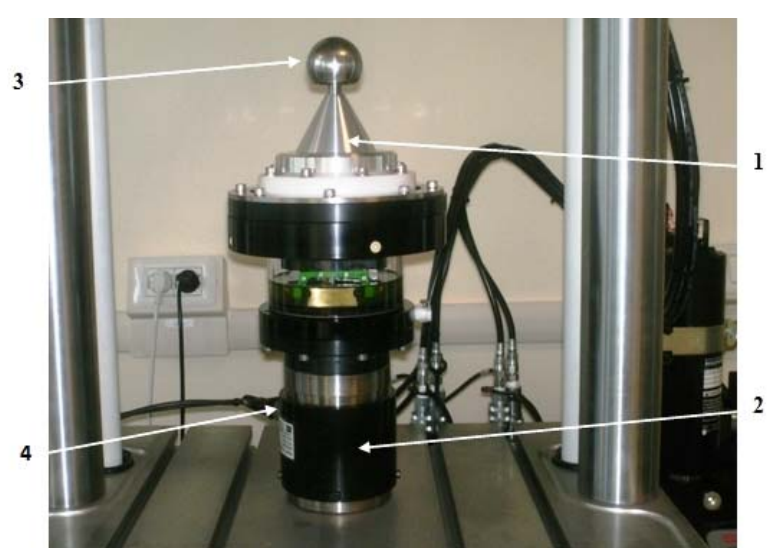

Fig. 6 Support of the femoral head: 1-sample grip support (replace the femoral stem); 2-axial force transducers; 3-MOMJ joint; and 4-moment torque transducer.

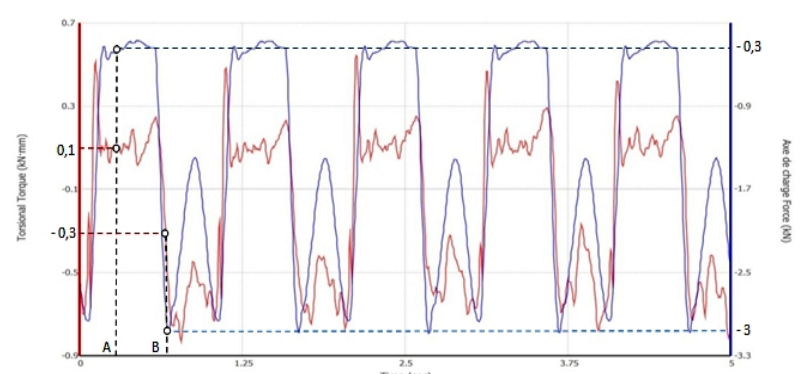

(a)

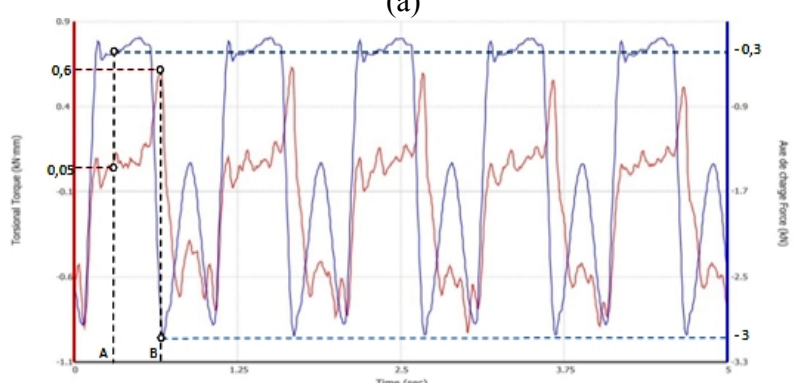

(b)

Fig. 7 The time graph of vertical contact force (blue) and of the friction moment (in red), at the MOMJ (a) and conventional MoP joint testing.

complete 5 cycles. Variation law of force and angles was established according to ISO 14242. In Fig. 7 the graph of the vertical contact force (blue) and of the moment of friction (in red) is presented, for the testing of the MoP conventional joint and the prototype MOMJ.

Fig. 8 shows the graph of a function of the vertical contact force (blue) and of the moment of friction (in red), in the testing of MOMJ joint and the conventional MoP hip joint implant. 


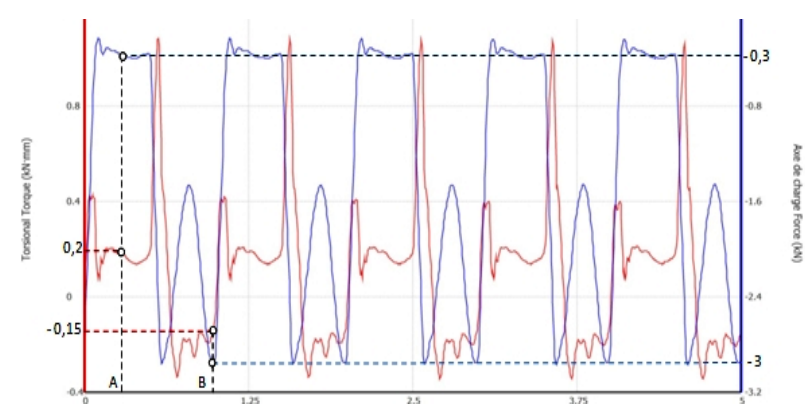

(a)

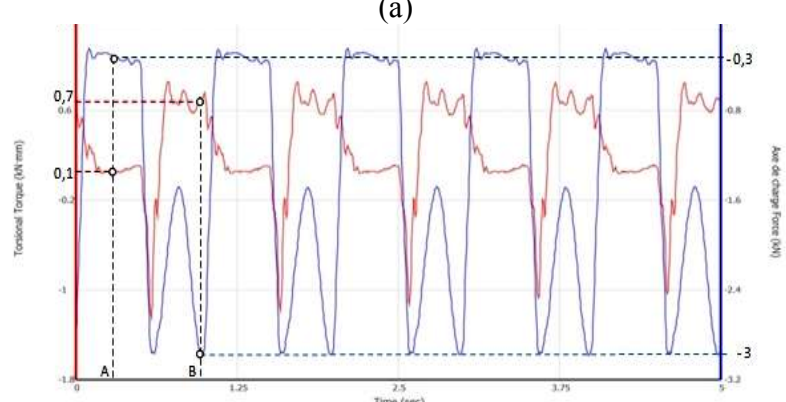

(b)

Fig. 8 Time graph of vertical contact force (blue) and of the moment of friction (in red), in testing of MOMJ and hip joint conventional MoP implant.

Points A and B of Figs. 7 and 8 are the points within a time sequences, in which the contact force and moment of torsion (recorded by MTS Bionix) have the highest value in a sequence of time. The moment of torsion is given by torsion transducer of MTS Bionix. Dividing its value by the radius of $14 \mathrm{~mm}$ the joint sphere, we obtain the value of the friction force.

The friction moment in a spherical joint is given by the relationship:

$$
M_{f}=\mu \cdot R \cdot W
$$

where, $M_{f}$ is torsional moment of friction, $\mu$ is friction coefficient, $R$ is the joint radius (in the case of the femoral head of $28 \mathrm{~mm}, R=14 \mathrm{~mm}=0.014 \mathrm{~m}), W$ is the resultant of forces $W_{x}, W_{y}, W_{z}$ from joint (mean the normal contact force on the joint), whose values have been set to $0.3 \mathrm{kN}$ minimum value and $3 \mathrm{kN}$ maximum value.

In the MOMJ joint case, $M_{f}$ is torsional friction torque of all frictions, recorded between the femoral head, balls, and acetabular cup.

On the basis of the presented charts, Tables 1 and 2 summarize the values of moment of friction recorded
Table 1 Values of the friction coefficient to MOMJ prototype testing.

\begin{tabular}{lllll}
\hline Graph & Point & $W(\mathrm{kN})$ & $M(\mathrm{kNmm})$ & $\mu$ \\
\hline Fig. 7a & A & 0.3 & 0.1 & 0.0238 \\
& B & 3 & 0.3 & 0.0072 \\
Fig. 7b & A & 0.3 & 0.005 & 0.0119 \\
& B & 3 & 0.6 & 0.0143
\end{tabular}

The average value of the global friction coefficient $\mu 0.0143$

Table 2 Values of the friction coefficient to conventional implant testing.

\begin{tabular}{lllll}
\hline Graph & Point & $W(\mathrm{kN})$ & $M(\mathrm{kNmm})$ & $\mu$ \\
\hline \multirow{2}{*}{ Fig. 8a } & A & 0.3 & 0.1 & 0.0238 \\
& B & 3 & 0.7 & 0.0167 \\
Fig. 8b & A & 0.3 & 0.1 & 0.0238 \\
& B & 3 & 0.5 & 0.0119
\end{tabular}

The average value of the global friction coefficient $\mu 0.0190$

and of the calculated global friction coefficient in testing of the prototype MOMJ, compared to conventional MoP implant testing.

It appears that when testing MOMJ joint, the medium value of global friction coefficient $(\mu=0.0143)$ is less than in the conventional MoP implant $(\mu=$ 0.0190 ), wich is particulary gratifying.

\section{Conclusions}

The studies presented in this paper are the result of over 15 years of research and have involved many complementary investigations such as those relating to the seizure and lubrication, materials and their surface condition, manufacturing technologies, and last but not least the calculation values of the efforts and determination of the mechanical mode of transmitting them between acetabular cup, the balls and the femoral head. Research has been difficult, as the goal of the establishment of a total hip prosthesis with rolling friction.

Because, during the years of theoretical studies, research and experimentation, the general trend was toward rejection of MoM, because it releases metallic ions which are potential carcinogens, this paper proposes only a new joint with rolling friction, which could potentially be used as a joint for total hip prosthesis. 
In this paper researchers found that new spherical joint with rolling friction, made based on an Omnitrack solution with low friction movement is a viable proposal, however it has some limitations. The materials used (SS316L) were not the latest generation ( $\mathrm{CoCr}$ or Ti6Al4V), although they had similar mechanical properties. Also, there were no tests done specifically intended for wear. The only findings were made on the wear at the end of the tests of friction (50,000 cycles), macroscopic and microscopic inspection of the femoral head, acetabular cup and balls. They have not shown evidence of any scratch made of wear debris, rolling balls traces on the femoral head and acetabular cup or seizure scars of the balls on the femoral head or acetabular cup.

Also, roundness deviations of the balls were not observed. Researchers face a surprising tribologic validation because the real contact area between the femoral head and acetabular cup that hols uploading should be higher in the case of classical MoP, at least theoretically. In the case of the proposed new joints MOMJ loading is transmitted through 106 balls with a $2.5 \mathrm{~mm}$ diameter.

The research has so far led to the requirement of further studies to elucidate this aspect. Future studies must also be focused on the wear surfaces inherent to this joint, in the same conditions of movement and loading, as well as on its character, and evaluation of wear amount depending on the principal factors of influence (material, load, relative speed). This involves finding a method for quantitative evaluation of precision value of wear.

\section{References}

[1] Liu, X. Y., Chu, P. K., and Ding, C. X. 2004. "Surface Modification of Titanium, Titanium Alloys, and Related Materials for Biomedical Applications." Materials Science and Engineering: R: Reports 47 (3-4): 49-121.

[2] Kustas, F. M., and Misra, M. S. 1992. Friction and Wear of Titanium Alloys. Vol. 18. Metals Park, OH: ASM Handbook Friction, Lubrication, and Wear Technology (ASM International).

[3] Molinari, A., Straffelini, G., Tesi, B., Bacci, T., and
Pradelli, G. 1997. "Effects of Load and Sliding Speed on the Tribological Behaviour of Ti-6Al-4V Plasma Nitrided Different Temperatures." Wear 203-204: 447-54.

[4] Fouquet, V., Pichon, L., Straboni, A., and Drouet, M. 2004. "Nitridation of Ti6Al4V by PBII: Study of the Nitrogen Diffusion and of the Nitride Growth Mechanism." Surface and Coatings Technology 186 (1-2): 34-9.

[5] Lanning, B. R., and Wei, R. H. 2004. "High Intensity Plasma Ion Nitriding of Orthopaedic Materials: Part II. Microstructural Analysis." Surface and Coatings Technology 186 (1-2): 314-9.

[6] Liu, C., Bi, Q., and Matthews, A. 2003. "Tribological and Electrochemical Performance of PVD TiN Coatings on the Femoral Head of Ti-6Al-4V Artificial Hip Joints." Surface and Coatings Technology 163-164: 597-604.

[7] Santos, L. V., Trava-Airoldi, V. J., Corat, E. J., Nogueira, J., and Leite, N. F. 2006. "DLC Cold Welding Prevention Films of a Ti6Al4V Alloy for Space Applications." Surface and Coatings Technology 200 (8): 2587-93.

[8] Osterle, W., Klaffke, D., Griepentrog, M., Gross, U., Kranz, I., and Knabe, Ch. 2008. "Potential of Wear Resistant Coatings on Ti-6Al-4V for Artificial Hip Joint Bearing Surfaces." Wear 264 (7-8): 505-17.

[9] Bemporal, E., Sebastiani, M., Staia, M. H., and Cabrera, E. P. 2008. "Tribological Studies on PVD/HVOF Duplex Coatings on Ti6Al4V Substrate." Surface and Coatings Technology 203 (5-7): 566-71.

[10] Avelar-Batista, J. C., Spain, E., Fuentes, G. G., Sola, A., Rodriguez, R., and Housden, J. 2006. "Triode Plasm Nitriding and PVD Coating: A Successful Pre-treatment Combination to Improve the Wear Resistance of DLC Coatings on Ti6Al4 Alloy." Surface and Coatings Technology 201 (7): 4335-40.

[11] Zhang, Z. X., Dong, H., Bell, T., and Xu, B. S. 2008. "The Effect of Deep-Case Oxygen Hardening on the Tribological Behaviour of a-C:HDLC Coatings on Ti6A14V Alloy." Journal of Alloys and Compounds 464: 519-25.

[12] Varenberg, M., Halperin, G., Etsion, I. 2002. "Different Aspects of the Role of Wear Debris in Fretting Wear." Wear 252 (11-12): 902-10.

[13] Zhou, Z., Rainforth, W. M., Tan, C. C., Zeng, P., Ojeda, J. J., Romero-Gonzalez, M. E., and Hovsepian, P. Eh. 2007. "The Role of Tribofilm and Roll-Like Debris in the Wear of Nanoscale Nitride PVD Coatings." Wear 263 (7-12): 1328-34.

[14] Holmberg, K. 1992. "A Concept for Friction Mechanisms of Coated Surfaces." Surface and Coatings Technology 56 (1): 1-10.

[15] Holmberg, K., Matthews, A., and Ronkainen, H. 1998. "Coatings Tribology — Contact Mechanisms and Surface 
Design.” Tribology International 31 (1-3): 107-20.

[16] Tanno, Y., and Azushima, A. 2009. "Effect of Counter Materials on Coefficients of Friction of TiN Coatings with Preferred Grain Orientations.” Wear 266 (11-12): 1178-84.

[17] Valero-Vidal, C., Casaban-Julian, L., Herraiz-Cardona, I., and Igual-Munoz, A. 2013. "Influence of Carbides and Microstructure of CoCrMo Alloys on Their Metallic Dissolution Resistance." Materials Science and Engineering: C 33 (8): 4667-76.

[18] Chelliah, N., and Kailas, S. V. 2009. "Synergy between Tribo-Oxidation and Strain Rate Response on Governing the Dry Sliding Wear Behaviour of Titanium." Wear 266: 704-12.

[19] Coli, B. F., and Pellman, M. A. 1998. "Metallurgical and Tribological Modification of Titanium and Titanium Based Alloys for Medical Devices by Plasma Assisted Techniques." In Technical Bulletin from Multi-Arc Scientific Coatings /Innovatique S.A.

[20] Rie, K.-T., Stucky, T., Silva, R. A., Leitao, E., Bordji, K., Jouzeau, J.-Y., and Mainard, D. 1995. "Plasma Surface Treatment and PACVD Coatings on Ti Alloys for Surgical Implants." Surface and Coatings Technology 74-75: 973-80.

[21] Pellman, M. 1998. "PVD Coatings for Medical Device Applications." In Technical Bulletin from Multi-Arc Scientific Coatings/Innovatique S.A.

[22] Ylbas, B. S., Sahin, A. Z., Ahmad, Z., and Aleem, B. J. A. 1995. "A Study of the Corrosion Properties of TiN Coated and Nitrided Ti-6Al-4V." Corrosion Science 37 (10): 1627-36.

[23] Yilbas, B. S., Sahin, A. Z., AlGarni, A. Z., Said, S. A. M., Ahmed, Z., Abdulaleem, B. J., and Sami, M. 1996. "Plasma Nitriding of Ti6Al4V Alloy to Improve Some Tribological Properties." Surface and Coatings
Technology 80: 287-92.

[24] Schutz, R. W., and Thomas, D. E. 1987. Corrosion of Titanium and Titanium Alloys. 9th edition. Metals Park, OH: ASM Corrosion-Metals Handbook, 669-705.

[25] Meletis, E. I., Erdemir, A., and Hochman, R. F. 1986. Ion Plating and Implantation Applications to Materials. Metals Park, OH: American Society for Metals, 173.

[26] Capitanu, L., Iarovici, A., Snisoru, J., Tiganesteanu, C., and Dima, M. 2008. "Dynamics of Hip Artificial Joints Wear." Journal of the Balkan Tribological Association 14 (1): 1221-4590.

[27] Capitanu, L., Badita, L. L, and Bursuc, D. C. 2011. "Damage of the Femoral Head of Total Hip Prosthesis." In Proceedings BALKANTRIB 2011, 217-25.

[28] Capitanu, L., Florescu, V., and Petrescu, F. 2000. "Tribological Aspects of Wear of Hip Joint Prosthesis." Presented at the First Mediterranean Tribology Conference, Jerusalem, Israel.

[29] Sadeghi-Mehr, M. 1997. "Investigations of Rolling Element Bearing for Hip Joint Prosthesis.” Ph.D. thesis, Imperial College of Science, Technology and Medicine.

[30] Katsuthasi, B., and Kiyoshi, S. 1992. Artificial joint. US Patent 5092898/0303.

[31] Davant, J. P. 1995. "Chirurgie de la Hance. Mieux Vivre avec une Prosthesis." Fonder l'Avenir 23: 53-6.

[32] Iarovici, A., Capitanu, L., Florescu, V., and Baubec, M. 2001. "Hip Joint Prosthesis with Rolling Bodies." Proceedings of the Romanian Academy-Series A: Mathematics and Physics, Technical Sciences, Information Science 1 (1-2): 37-44.

[33] Iarovici, A., Capitanu, L., Florescu, V., Baubec, M., and Petrescu F. 2001. "Hip Joint Prosthesis with Rolling Bodies, Part I-The Balls Arrangement Analysis." In Proceedings of the Annual Symposium of the Institute of Solid Mechanics, 251-8. 